\title{
Small mammal trapping in tropical montane forests of the Upper Nilgiris, southern India: an evaluation of capture-recapture models in estimating abundance
}

\author{
KARTIK SHANKER \\ Centre for Ecological Sciences, Indian Institute of Science, Bangalore 560 012, India \\ Address for correspondence: A1/4/4, 3rd Main Road, Besant Nagar, Chennai 600 090, India \\ (Fax, 91-44-4934862; Email, kartik69@usa.net)
}

\begin{abstract}
Capture-mark-recapture was used to study small mammal populations in tropical montane forests in southern India. Eleven plots in six montane forest patches were sampled from February-October, 1994. Six species were captured, including four rodents and two shrews. PROGRAM CAPTURE was used to derive estimates of density of the most abundant species in the study area, Rattus rattus Linnaeus. The coefficient of variation of the density estimate was used as an index of precision. The coefficient of variation decreased exponentially with increasing capture probability and with an increase in trapping duration. The coefficient of variation and the capture probability were not correlated with estimates of density. The density estimate increased with trapping duration, as did trap mortality. The latter may have been due to the trend of increased mortality with recaptures of the same individual, which in turn may have been due to weight loss over consecutive captures. Estimates of density derived using four estimators were different for 2, 3, 4 and 5 days of trapping. The coefficient of variation was highest for the generalized removal estimate and lowest for Darroch's estimate. The models and estimators could not be applied to more than one species, and for this species, only in select habitats in a few seasons. Therefore, models of density estimation developed for temperate areas may not be suitable for tropical habitats due to low densities of small mammals in these habitats.
\end{abstract}

\section{Introduction}

Animal biologists are interested in the population size of animals, whether they are community ecologists, wildlife managers, conservationists or population ecologists. Consequently, the estimation of abundance has been a critical issue in the study of mammals (Seber 1982). The earliest efforts to estimate population size date back at least to the 17 th century. Methods involving marked animals or capture-mark-recapture (CMR) were independently discovered several times, beginning with P S Laplace in 1783. Peterson (1896) may have been the first to express the fundamental principle of the CMR method. Later, Lincoln (1930) and Jackson (1933) independently formulated the basic principle of capture-recapture. While CMR and removal sampling are still considered useful in specific situations, their usefulness may have been overrated in the biological literature (White et al 1982). Numerous attempts have been made to formulate a unified approach to density and abundance estimation (Otis et al 1978; White et al 1982; Pollock et al 1990). In fact, there has been a move, in recent years, towards the testing of hypotheses of biological interest rather than estimation of numerical quantities such as population size and survival rate (Lebreton et al 1992; Nichols 1992).

The key parameter in the estimation of population size using CMR is capture probability (Otis et al 1978; Seber 1982; Nichols and Pollock 1983). This is the probability of capture of a given individual during a single sampling session; the proportion of a population captured during a single sampling session will thus depend on the capture probability of each individual. The simplest models assume that the capture probability of all individuals are constant over time and are not altered by capture/marking/ handling. However, in nature, capture probabilities are rarely equal and the literature abounds with statistical efforts to overcome this essential confounding variable i.e., unequal capture probability. In fact, the need to deal with

Keywords. Capture probability; coefficient of variation; estimators; Rattus rattus; trap mortality 
these methodological assumptions has resulted in the development of complex procedures and statistics, requiring large software systems for satisfactory analysis (Nichols et al 1981; Brownie and Pollock 1985). There is some effort to render the methods usable to non-mathematically oriented biologists (Minta and Mangel 1989; Wileyto et al 1994), and to analyse cost functions (Skalski 1985). At this point, however, it seems that the tropical biologist must return to direct enumeration for the large part, while occasionally indulging in CAPTURE or other procedures. These methods and their history have been extensively reviewed in Smith et al (1975), Otis et al (1978), Seber (1982) and more recently by Nichols (1992).

The assumption of closure is central to most CMR models. The concept can be divided into two components (White et al 1982): (i) Geographic closure, by a physical boundary, that limits the population and (ii) demographic closure, to births, deaths, immigration and emigration.

Models for open populations depend on geographic closure, but they allow mortality + emigration and birth + immigration rates to be estimated. The fundamental assumptions of CMR studies are:

(i) The population is closed (though demographic closure is relaxed in open models).

(ii) Animals do not lose their marks during the experiment.

(iii) All marks are noted and recorded correctly at each sampling occasion.

The Petersen Lincoln estimator (Petersen 1896), which is the earliest estimator developed for estimating the size of populations from CMR studies is simply:

$$
N=\frac{n_{1} n_{2}}{m_{2}}
$$

where $n_{1}$ and $n_{2}$ are the total number of animals captured on the first and second sampling sessions and $m_{2}$ is the number of marked animals captured on the second sampling session. The Schnabel (1938) estimator is used when there are more than two sampling sessions. These estimators assume that capture probabilities are equal for all animals in the population throughout the trapping period. However, when there is heterogeneity of capture probabilities among individuals, these estimators are severely negatively biased (Carothers 1973). Computer simulations also show that heterogeneity can cause substantial bias in the estimators (Burnham and Overton 1969; Carothers 1973).

Models have been developed to deal with three sources of variation in capture probabilities: (i) time $M_{\mathrm{t}}$, (ii) behavioural response $M_{\mathrm{b}}$, and (iii) individual heterogeneity $M_{\mathrm{h}}$ (Otis et al 1978). In the null model, $M_{\mathrm{o}}$, the capture probabilities are assumed to be equal for all animals over time. In model $M_{\mathrm{t}}$, capture probabilities change from one trapping period to the next, but within a period, they are constant for all animals. In the second case, $M_{\mathrm{b}}$, all animals initially have the same probability of capture. After the first capture, they become trap happy (the capture probability increases) or trap shy (capture probability decreases). In the last model, $M_{\mathrm{h}}$, each individual has a unique capture probability which may be due to age, sex or some inherent characteristic. Otis et al (1978) describe 8 models, the others being combinations of the above, i.e., $M_{\mathrm{tb}}, M_{\mathrm{th}}, M_{\mathrm{bh}}$ and $M_{\mathrm{tbh}}$. Estimators have been derived for 5 of the models (White et al 1982). The model selection procedure of PROGRAM CAPTURE involves the computation of significance values for each of the estimators based on a series of statistical tests; these values are subsequently subjected to multivariate discriminant function analysis to derive a selection criterion (Otis et al 1978).

Despite a large body of work, when density estimates are required, there still does not seem to be a clear system for choosing a method, given that the habitats and the species being studied are so highly variable. Many small mammal biologists still depend on the direct enumeration method proposed by Krebs (1966). Despite the criticism of the minimum number alive (MNA) (Jolly and Dickson 1983; Nichols and Pollock 1983), it continues to be used in the absence of a truly user-friendly alternative. PROGRAM CAPTURE (Otis et al 1978; White et al 1982), which models capture probabilities and estimates abundance using appropriate estimators, may offer the best alternative, though it has been heavily criticised by Menkens and Anderson (1988). Its model selection procedure performs poorly when sample sizes are small (Otis et al 1978; White et al 1982) and since many studies deal with small populations or low capture probabilities, the usefulness of PROGRAM CAPTURE may be limited (Menkens and Anderson 1988). Direct enumeration is not sensitive to population size, survival between trapping intervals and individual heterogeneity. However, if the capture probability is below $0 \cdot 5$, it provides a poor estimate of population size. It is also very sensitive to reduced capture probabilities for unmarked animals (Hilborn et al 1976).

While other methods [O' Farrell's (O' Farrell et al 1977) method, Jolly-Seber method, and PROGRAM CAPTURE] have been used in small mammal studies, many authors continue to use direct enumeration (e.g., Murua et al 1987; Turner and Grant 1987; Iriarte et al 1989; O' Connell 1989; Patterson et al 1989; Boonstra and Boag 1992; Scott and Dueser 1992; Wirminghaus and Perrin 1993; Diffendorfer et al 1995; Doonan and Slade 1995; Jedrzejewski et al 1995), and catch per effort (Stephenson 1993; McMurry et al 1994; Steen et al 1996) to estimate density in temperate and tropical small mammal studies. Due to low densities of small mammals in many habitats, many authors may be forced to use estimation methods such as direct enumeration and catch per effort, and models designed for temperate areas may be inappropriate for CMR studies in tropical areas.

In this paper, I examine density estimates and their precision for a small mammal species in the Upper Nilgiris to identify problems in density estimation. In the study, the 
most abundant species was the white-bellied wild subspecies of the common rat, Rattus rattus Linnaeus. It was found in different habitats sampled in the Upper Nilgiris (montane forests and plantations) and was the most abundant in most of the habitats where it was trapped (Shanker 1998). However, the analysis is confined to the montane stunted evergreen forest where it was most abundant and the following questions are addressed with regard to density estimation:

(i) What are the factors that influence the density estimate?

(ii) How does trap-mortality vary during the trapping session?

(iii) Can trapping effort be optimized?

(iv) Is there a reliable estimator for estimating densities?

\section{Materials and methods}

\subsection{Study area}

The Nilgiris are located between $11^{\circ} 10^{\prime}-11^{\circ} 30^{\prime} \mathrm{N}$ and $76^{\circ} 25^{\prime}-77^{\circ} 00^{\prime} \mathrm{E}$ at the junction of the Eastern Ghats and the Western Ghats, in southern India. The study was conducted in the montane ecosystem (1800-2500 msl) of the Nilgiris, which comprises of patches of stunted evergreen forest (locally known as 'shola') surrounded by grasslands. Though most grasslands have been replaced by exotic species such as wattle (Acacia spp.), pine (Pinus roxburghii), tea (Camellia sinensis) and bluegum (Eucalyptus globulus), the natural ecosystem remains intact in the southwest region of the Upper Nilgiris plateau. The shola patches, usually $1-10$ ha in size with few exceeding 100 ha, are confined to depressions and folds in the mountain. They are extremely dense, with 5,000 or more woody plants (> $1 \mathrm{~cm} \mathrm{dbh}$ ) per hectare, and are dominated by the families Lauraceae, Rubiaceae and Symplocaceae (H S Suresh and R Sukumar, unpublished data). There is a sharply defined ecotone between the sholas and the grasslands which is maintained by frost and fire (MeherHomji 1984). The climate is highly seasonal, with a dry season extending from December to February, a premonsoon season from March to May, the southwest monsoon from June to August and a second wet season from September to November. Most of the areas sampled receive annual rainfall of 1500-2000 $\mathrm{mm}$.

\subsection{Sampling methods}

Six montane evergreen forest patches, ranging in size from 2 ha to 60 ha, were selected for sampling. Eleven plots were established and sampled in these patches; four 0.49 ha plots in four small patches (2-10 ha), two 0.49 ha plots in one medium patch (60 ha) and three 0.49 ha plots and two 1 ha plots in one large patch (600 ha). Traps were placed at intervals of 10 metres so that each 0.49 ha plot consisted of 49 permanently marked trap stations, in a square grid of $7 \times 7$ traps (the 1 ha plots had 100 trap stations, in a $10 \times 10$ configuration). A standard Sherman live trap $(22.9 \times 7.6 \times 8.9 \mathrm{~cm})$ was placed on the ground at each station, close to a tree, log, or any other appropriate runway. The traps were baited with grated coconut and rice. All trapped animals were identified, ear-punched, sexed, weighed, measured and released. The traps were checked once daily between $0800 \mathrm{~h}$ and $1200 \mathrm{~h}$. The plots were run for five consecutive nights during January-October 1994; trapping was carried out seasonally with each 0.49 ha plot being sampled once each season, giving a total of three to four sampling sessions for each plot. The 1 ha plots were sampled once during the last sampling session, giving a total of about 7,615 trap nights. The four sampling sessions correspond to different seasons, session 1 being the dry season (February to April), session 2 the early wet season (May-July) and sessions 3 and 4 the late wet season (August-October).

\subsection{Analysis}

While CMR models estimate the population size, they do not estimate the sampled area, and hence they provide estimates of abundance rather than density. Many methods are available to estimate the area sampled to calculate densities (Smith et al 1975). In this analysis, the area of the trapping plots was assumed to be the sampled area for the calculation of densities. The estimation of density was restricted to $R$. rattus because it was the only species captured in sufficient numbers to apply the models. Minimum number alive (MNA) estimates, which tally all different individuals known to be alive in the sampled area, were derived from the data. Some sessions could not be analysed because the number of captures was too low. The other sampling sessions were analysed using PROGRAM CAPTURE (White et al 1982) to derive the following information for 2, 3, 4 and 5 days of sampling:

(i) Model selection.

(ii) Estimate of $N$ using the appropriate estimator (as suggested by the program).

(iii) Estimate of $N$ using the null estimator $\left(N_{\mathrm{o}}\right)$, based on the null model $\left(M_{\mathrm{o}}\right)$.

(iv) Estimate of $N$ using Darroch's estimator $\left(N_{\mathrm{d}}\right)$, based on the time variation model $\left(M_{\mathrm{t}}\right)$.

(v) Estimate of $N$ using the generalized removal estimate, based on removal $N_{\mathrm{r}}$.

(vi) The standard errors (SE) for each of the above.

(vii) The capture probability of the animals in the null model.

The coefficient of variation $(\mathrm{CV})$ was used as an index of precision, $\mathrm{CV}=\mathrm{SE} \times 100 / N$.

Trap mortality was calculated for each trapping session in the following ways: 
(i) All animals dead on each day, AD.

(ii) Proportion of animals dead on each day; $\mathrm{PD}=$ number of animals dead/number of animals caught.

(iii) Cumulative dead as a proportion of total; $\mathrm{TD}=$ total number of animals dead up to day $x /$ total number of animals caught up to day $x$.

(iv) Death as a function of capture history; $\mathrm{CD}=$ number of animals that died at capture $1,2,3 \ldots$.number of animals caught $1,2,3 \ldots$ times.

(v) Proportion of new animals dead: number of unmarked (new) animals dead on day $x$ /number of animals caught on day $x$.

Comparisons of estimates, CVs and indices of mortality for 1-5 days of trapping were tested using non-parametric tests (Siegel and Castellan 1988). Correlations were calculated using Pearson's product moment correlation test.

\section{Results}

\subsection{Small mammals in montane evergreen forests}

Six species of small mammals were trapped in the montane evergreen forests from February to October 1994. These included four rodents $-R$. rattus, Bonhote's field mouse Mus famulus, spiny field mouse Mus platythrix, and Malabar spiny dormouse Platacanthomys lasiurus-and two species of shrews Suncus murinus and Suncus dayi. $R$. rattus was the most abundant with a total of 376 individuals; its density (MNA) ranged from 2 to 44 animals/ha, and was frequently of the order of 5-15 animals/ha. Densities of other species ranged from 0 to 10 animals/ha and were usually of the order of 1-2 animals/ha. The capture probabilities for $R$. rattus varied from 0.17 to 0.64 (mean $=0.43$ ). In $R$. rattus, trap mortality (cumulative proportion dead, TD, on day 5) was as high as $50 \%$, with a mean of $15 \%$.

\subsection{Factors that influence the estimate}

The capture probability was not different when estimated from 3, 4 and 5 days of trapping; however the capture probability estimated from 2 days of trapping was higher than the others (Friedman $P<0.05$ ) (figure 1a). The capture probability was correlated with rainfall, being higher during the wet season (sampling sessions 3 and 4) than the dry season (sessions 1 and 2) (Friedman $P<0.05)$ (figure 1b).

The estimate based on the null model $\left(N_{\mathrm{o}}\right)$ and MNA did not vary with capture probability (figure $2 \mathrm{a}, \mathrm{b}$ ). $N_{\mathrm{o}}$ did however increase with the number of days of trapping (Friedman $P<0.001$ ) with the estimates derived from days 4 and 5 being significantly higher than those derived from days 2 and 3 (table 1). The coefficient of variation did not vary significantly with MNA, or with the estimate, $N_{\mathrm{o}}$ (figure $2 \mathrm{c}, \mathrm{d})$. However, it decreased with an increase in the capture probability (figure 3 ) and also with the number of sampling days $(r=0 \cdot 37 ; n=107 ; P<0 \cdot 01)$ (figure 1a).

\subsection{Variation in mortality over the trapping period}

Trap mortality increased with the number of days of trapping (figure $4 a, b)$. Significantly, the cumulative proportion of animals dead (TD) increased $(r=0.31, n=116$, $P<0.001$ ) (figure $4 \mathrm{c}$ ), implying that as the trapping session increased in duration, a larger proportion of the population was being lost to trap mortality. There
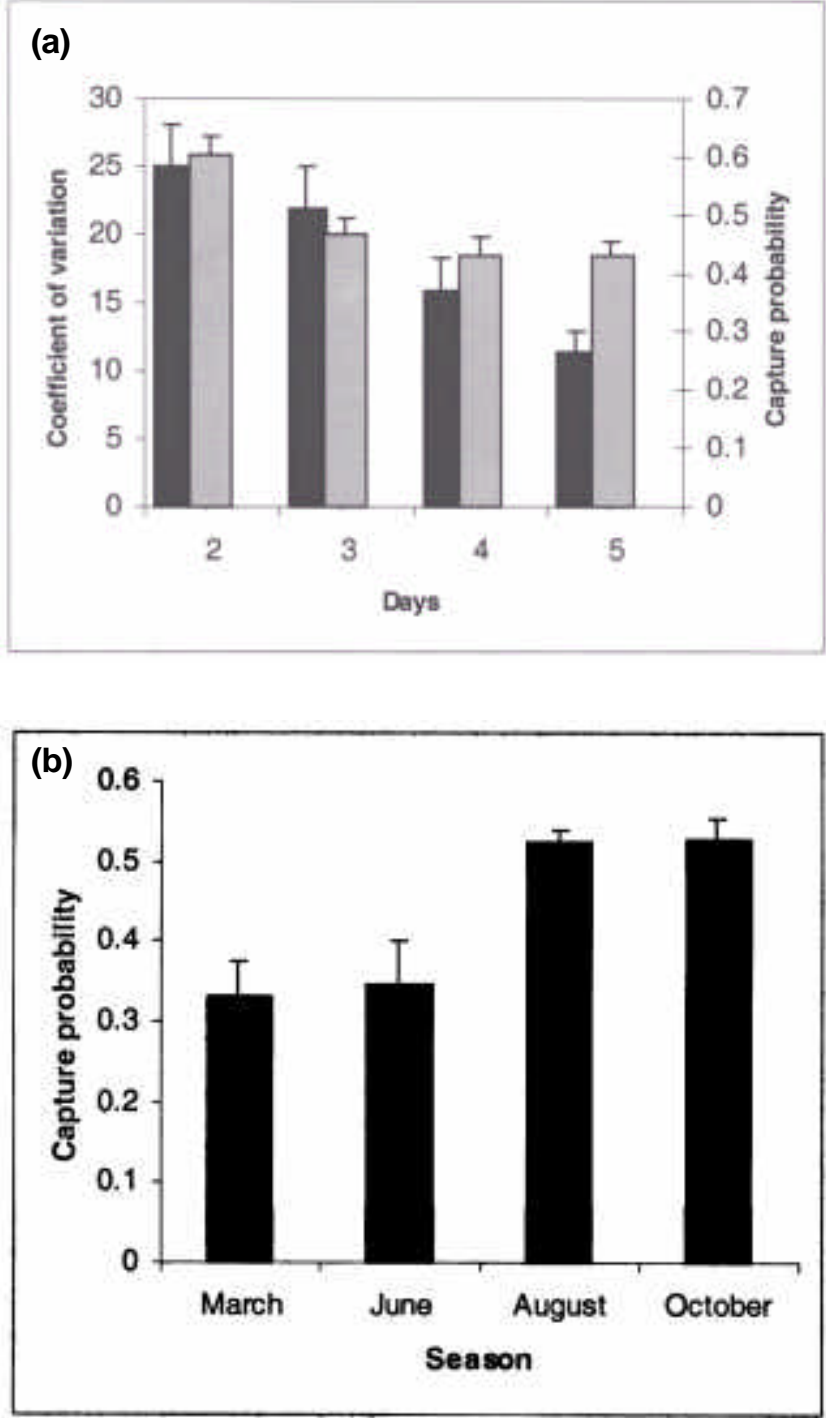

Figure 1. (a) While capture probability (as calculated using the null estimator, $N_{\mathrm{o}}$ : gray bars) as estimated from 3, 4 and 5 days of trapping were not different, the coefficient of variation of the estimate $N_{\mathrm{o}}$ (black bars) decreased from day 2 to day 5. (b) Capture probability was higher during the wet season than during the dry and early wet season. 
was a trend towards increased mortality with each recapture (figure 4d; average CD increased significantly with the number of captures; $r=0.89, n=5$, $P<0.001)$. There was no difference in the mortality of new animals (ND) over the trapping period (figure 4e). This means that the increase in animals dead (AD: figure $4 a$ ) and proportion dead (PD: figure $4 b$ ) was due to the increased mortality of recaptured animals (CD: figure 4d).

$R$. rattus showed a decrease in weight with each consecutive capture (figure 5). Animals lost an average of 3.8\% of their body weight after a single capture. R. rattus is

was not different between days 3 and 4, though it was different between days 4 and 5 and between days 3 and 5 (Friedman $P<0.001$ ).

\subsection{Differences based on patch size}

The sholas were classified into small patches (below 10 ha; number of sampling sessions, $n=10)$, medium patch (60 ha; $n=7)$ and a large patch (600 ha; $n=12)$. There was no significant difference between the small, medium and large patches for the following parameters: MNA, capture

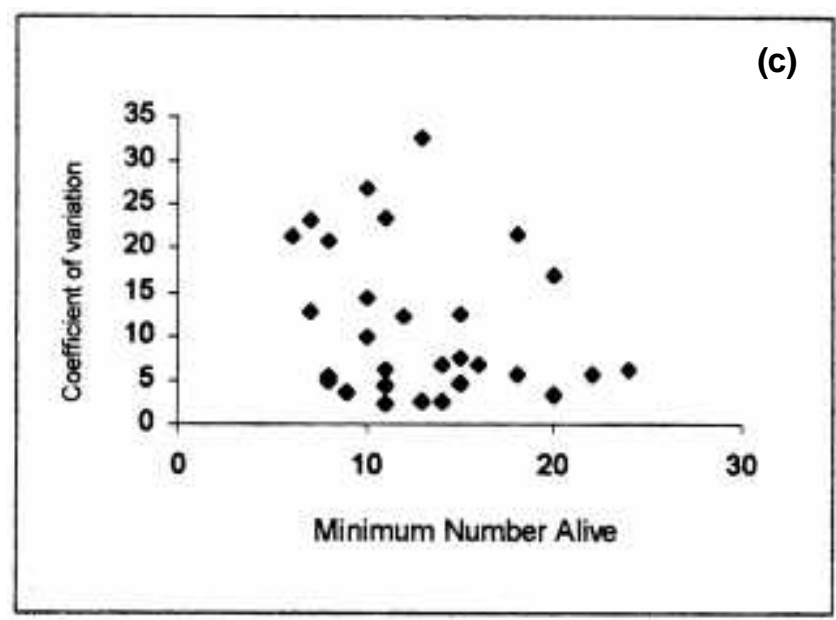

(b)

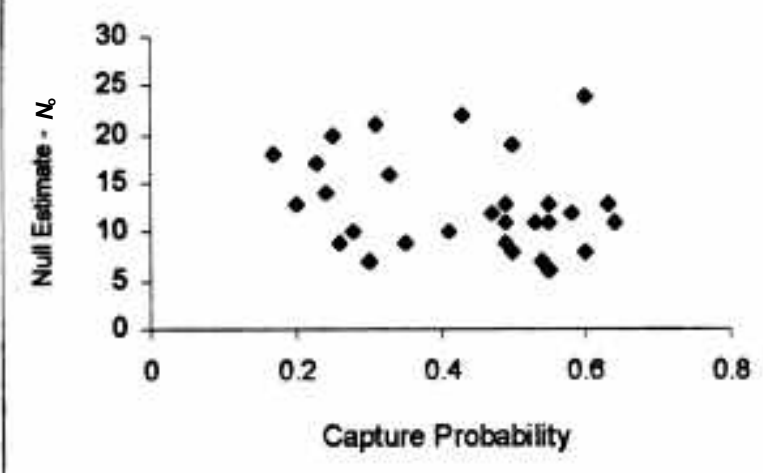

Figure 2. Capture probability was not correlated with the (a) minimum number alive (MNA) or (b) null estimate, $N_{0}$. The coefficient of variation was not correlated with (c) minimum number alive or (d) null estimate, $N_{\mathrm{o}}$.

known to be a nocturnal forager and when trapped, may be unable to spend sufficient time foraging. The loss in weight by the fifth consecutive capture was $15 \%$ of the original body weight. Combined with the cold and rain, this may have resulted in higher mortalities with increased recaptures. This would explain higher mortality towards the end of capture period. The cumulative proportion dead (TD) probability, estimate $N_{\mathrm{o}}$, and the coefficient of variation (Kruskal-Wallis one way analysis of variance). However, within each of the groups, there appeared to be a difference in the patterns (table 1). Significantly, small and medium patches showed no difference in the estimate $N_{\mathrm{o}}$ based on 2 , 3,4 and 5 days of trapping. The estimates derived from days 4 and 5 were significantly higher than those derived from 
Table 1. Estimates of abundance derived using three estimators - the null estimator $\left(N_{\mathrm{o}}\right)$, Darroch's estimator $\left(N_{\mathrm{d}}\right)$ and the generalized removal estimator $\left(N_{\mathrm{r}}\right)$, and their coefficients of variation from $2,3,4$ and 5 days of trapping. ${ }^{a}$

\begin{tabular}{|c|c|c|c|c|c|c|c|c|}
\hline & $N_{\mathrm{o}}$ & $\begin{array}{l}\mathrm{CV} \\
(\%)\end{array}$ & $N_{\mathrm{r}}$ & $\begin{array}{l}\mathrm{CV} \\
(\%)\end{array}$ & $N_{\mathrm{d}}$ & $\begin{array}{l}\mathrm{CV} \\
(\%)\end{array}$ & MNA & $\begin{array}{l}\text { Capture } \\
\text { probability }\end{array}$ \\
\hline \multicolumn{9}{|l|}{2 day estimates } \\
\hline Small $(n=10)$ & $8 \cdot 4$ & $23 \cdot 4$ & $10 \cdot 5$ & $20 \cdot 0$ & & & $7 \cdot 3$ & 0.6 \\
\hline Medium $(n=7)$ & $8 \cdot 3$ & $24 \cdot 6$ & $8 \cdot 7$ & $22 \cdot 7$ & & & $6 \cdot 1$ & $0 \cdot 6$ \\
\hline Large $(n=12)$ & $10 \cdot 2$ & $25 \cdot 0$ & $11 \cdot 8$ & $22 \cdot 1$ & & & $8 \cdot 1$ & $0 \cdot 6$ \\
\hline \multicolumn{9}{|l|}{3 day estimates } \\
\hline Small $(n=10)$ & $9 \cdot 5$ & $19 \cdot 0$ & $12 \cdot 4$ & $21 \cdot 6$ & $9 \cdot 4$ & $11 \cdot 5$ & $9 \cdot 2$ & $0 \cdot 48$ \\
\hline Medium $(n=7)$ & $11 \cdot 0$ & $27 \cdot 5$ & $12 \cdot 3$ & $24 \cdot 7$ & $11 \cdot 4$ & $17 \cdot 3$ & $8 \cdot 3$ & 0.44 \\
\hline Large $(n=12)$ & $13 \cdot 3$ & $20 \cdot 7$ & $17 \cdot 9$ & $25 \cdot 6$ & $14 \cdot 1$ & $14 \cdot 5$ & $11 \cdot 6$ & 0.47 \\
\hline \multicolumn{9}{|l|}{4 day estimates } \\
\hline Small & $10 \cdot 0$ & $16 \cdot 8$ & $14 \cdot 8$ & $23 \cdot 7$ & $10 \cdot 2$ & $9 \cdot 2$ & $10 \cdot 6$ & 0.45 \\
\hline Medium & $11 \cdot 3$ & $16 \cdot 6$ & $14 \cdot 6$ & $26 \cdot 3$ & $10 \cdot 3$ & $9 \cdot 7$ & $9 \cdot 9$ & $0 \cdot 44$ \\
\hline Large & $15 \cdot 1$ & $13 \cdot 5$ & $21 \cdot 3$ & $23 \cdot 0$ & $13 \cdot 5$ & $9 \cdot 8$ & $14 \cdot 0$ & $0 \cdot 45$ \\
\hline \multicolumn{9}{|l|}{5 day estimates } \\
\hline Small & $10 \cdot 7$ & $10 \cdot 7$ & $16 \cdot 1$ & $19 \cdot 0$ & $10 \cdot 4$ & $6 \cdot 5$ & $11 \cdot 5$ & $0 \cdot 41$ \\
\hline Medium & $11 \cdot 3$ & $13 \cdot 0$ & $13 \cdot 4$ & $18 \cdot 0$ & $10 \cdot 3$ & $8 \cdot 5$ & $10 \cdot 6$ & 0.42 \\
\hline Large & $15 \cdot 7$ & $11 \cdot 0$ & $21 \cdot 5$ & $21 \cdot 6$ & $13 \cdot 8$ & $2 \cdot 4$ & $15 \cdot 6$ & 0.45 \\
\hline
\end{tabular}

${ }^{a}$ The estimates and CVs are averaged for all plots and samplings sessions in each size class. Four small patches, each with a single 0.49 ha plot, were sampled two to four times $(n=10)$; the medium sized patch (60 ha) had two 0.49 ha plots $(n=7)$; the large patch $(600 \mathrm{ha})$ had three 0.49 ha plots, sampled two to four times and two 1 ha plots which were sampled once $(n=12)$. MNA is the minimum number alive and capture probability is estimated using the null model.

days 2 and 3 in the large patch. The coefficient of variation was significantly lower on each successive day for large patches (Friedman $P<0.001$ ). A trend towards lower coefficient of variation with increased trapping duration was also observed in small and medium patches.

\subsection{Model selection by PROGRAM CAPTURE}

For 2 days of trapping, the model $M_{\text {tbh }}$ (model based on variations in time, behaviour and heterogeneity) was chosen most frequently, i.e., in $75 \%$ of the sessions $(n=29)$. Since there is no estimator for this model (White et al 1982), the null estimator $N_{\mathrm{o}}$ was used. For 3 days of trapping, $M_{\mathrm{o}}$ was chosen for $78 \%$ of the samples, $M_{\mathrm{th}}$ for $11 \%$ and $M_{\mathrm{tbh}}$ for $7.5 \%$. With 4 days of trapping, $M_{\mathrm{o}}$ was selected $79 \%, M_{\mathrm{tbh}}$ $10 \%$, and $M_{\mathrm{h}} 7 \%$ of the samples. For the 5 day sample, $M_{\mathrm{o}}$ was selected for $72 \%, M_{\mathrm{h}} 10 \%$, and $M_{\mathrm{tbh}} 6 \%$ of the samples. The largest number of different estimators (6) was selected for 5 days of trapping (Appendix 1).

\subsection{Comparing the estimators}

For a comparison between 3, 4 and 5 days of trapping, the null estimator and the generalized removal estimator were applied for all sessions (total number of sessions, $n=29$ ) and Darroch's estimator $(n=17)$ was applied based

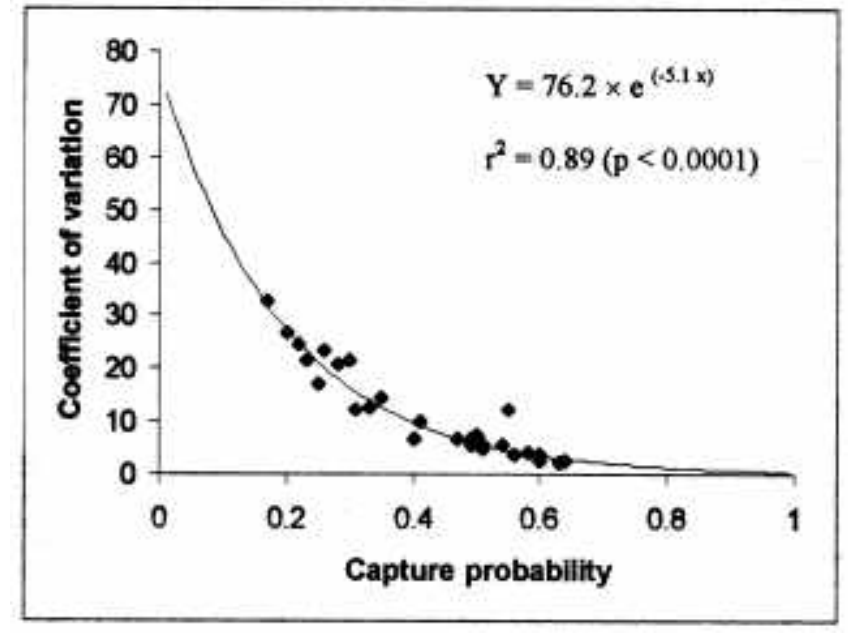

Figure 3. The coefficient of variation of the estimate $\left(N_{\mathrm{o}}\right)$ decreased with an increase in the capture probability as estimated from 5 days of trapping (Pearson's $r=0.93 ; n=29$; $P<0 \cdot 0001)$.

on models suggested by the program (tables 1 and 2). The Jackknife estimator was suggested by PROGRAM CAPTURE for a few sessions (8, 6 and 5 for 3,4 and 5 days of capture) and was not included in the comparative analysis. 
The estimate, $N_{\mathrm{d}}$, derived from Darroch's estimator, was significantly higher on days 4 and 5 than day 3 (Friedman $P<0.05)$. Estimates derived from days 4 and 5 were not different from each other. The coefficient of variation of the estimate, however, decreased from day 3 to 5 (Friedman $P<0.05)$. The estimate derived using the generalized removal estimator was higher on day 3 than day 2 and higher on days 4 and 5 than day 3 (Friedman $P<0.0001$ ). The coefficients of variation of this estimator were, however, not different on days 3,4 and 5. Estimates of $N$ derived from the various estimators were different from each other for 2, 3, 4 and 5 days of sampling (Friedman $P<0.001$ ).
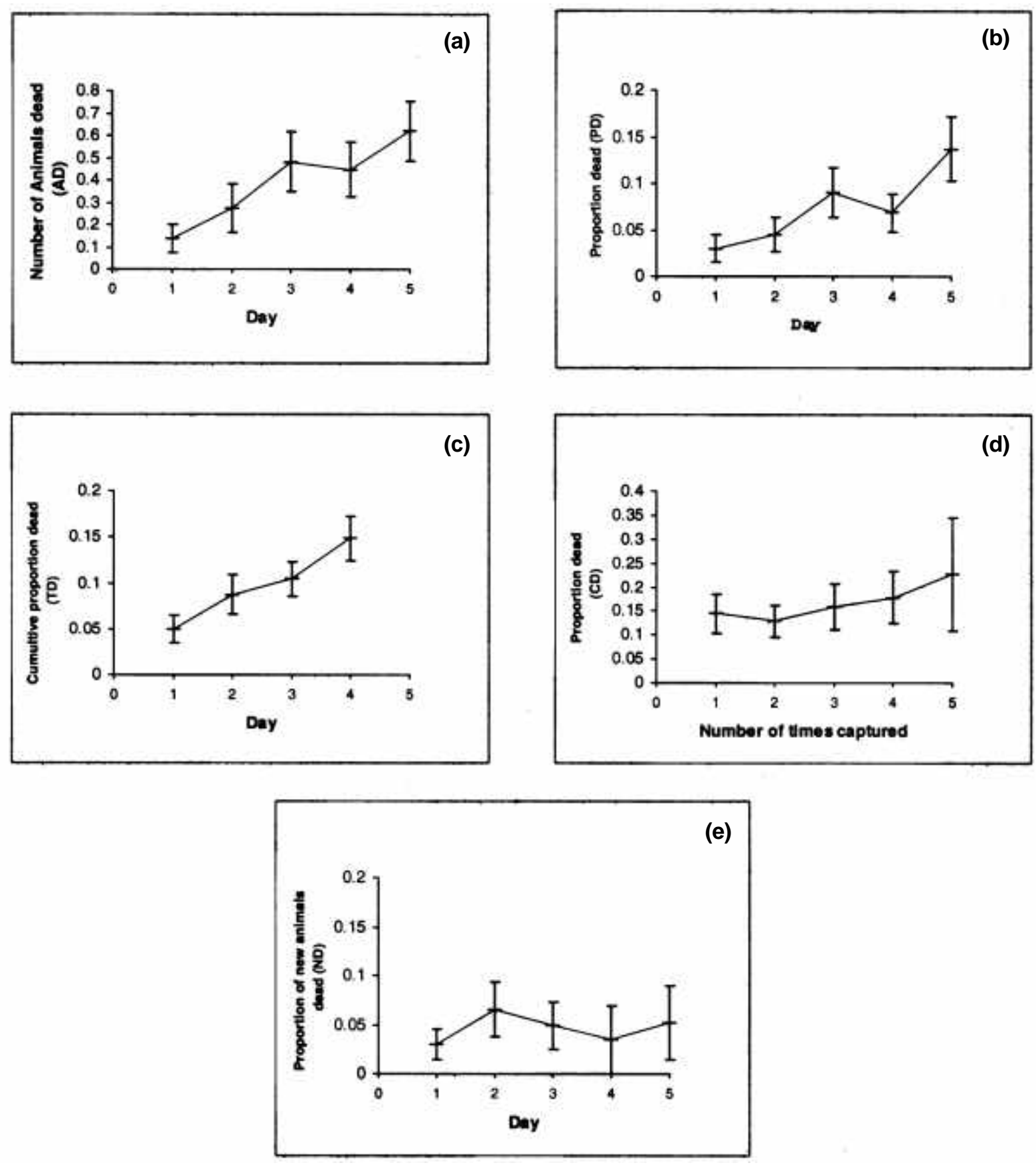

Figure 4. (a) The number of animals dead on each day increased with the number of trapping days $(r=0 \cdot 25$; $n=145 ; P<0.01)$ as did (b) the proportion of animals dead on each day. (c) There was an significant increase in the cumulative proportion of animals dead with the number of days of trapping $(r=0.31 ; n=116 ; P<0 \cdot 01)$. (d) There was also a trend towards increased mortality with consecutive recaptures of the same individual. (e) There was no difference in the number of new animals caught on each day. 
The generalized removal estimator was the highest regardless of the number of trapping days. Darroch's estimator was the lowest for 3 days of trapping. The null estimator and Darroch's estimator were not different for 4 and 5 days of trapp- ing. The coefficient of variation was not different for 2 days of trapping. For 3, 4, and 5 days of trapping, Darroch's estimator had a lower CV than the null estimator and the generalized removal estimator (Friedman $P<0.05$ ).

\section{Discussion}

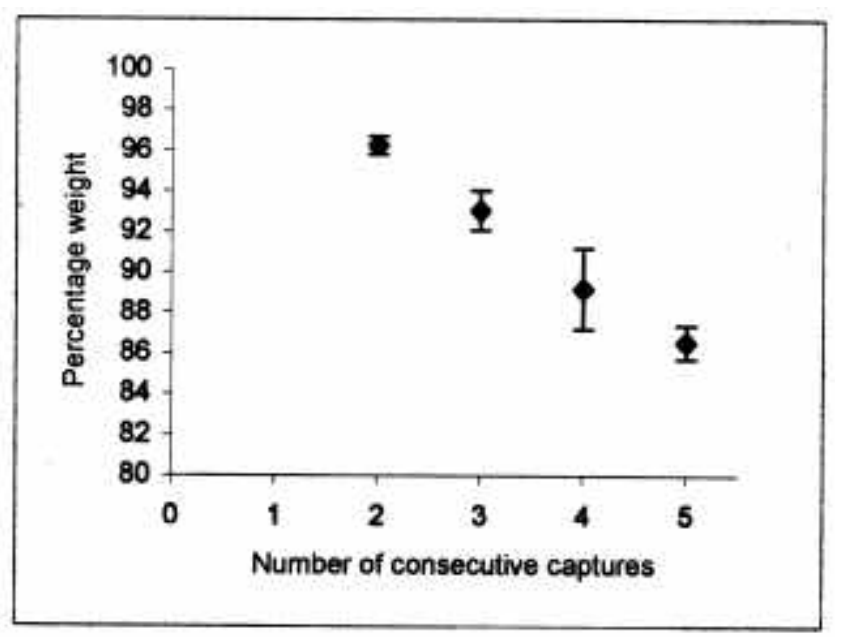

Figure 5. There was a loss in body weight of $R$. rattus with consecutive captures. The percentage weight decreased with each successive capture.
There is considerable variation in the density of small mammals in tropical evergreen forests, with some areas ranging from $\mathrm{ca}$. 0.5 to 25 rodents/ha (Jeffery 1977; IsabiryeBasuta and Kasenene 1987; O' Connell 1989; Mares and Ernest 1995), while others range from $4 \cdot 1$ to $4 \cdot 9 /$ ha (Harrison 1969) and $0 \cdot 7$ to $4 \cdot 9 /$ ha (August 1983). In southern India, a few studies report mean densities of the order of 15 rodents/ha for mid elevation moist evergreen forests (Chandrasekar-Rao and Sunquist 1996; Shanker 1998), while other studies have shown much lower densities in mid and low elevation evergreen forests (Meena 1997; K Shanker unpublished data; D Mudappa unpublished results). In this study, the MNA of the most abundant species, $R$. rattus, never exceeded 44 animals/ ha and was more frequently of the order of 5 to 15 animals/ha (Shanker 1998). It is evident, however, that $R$. rattus densities are low in these habitats, and densities recorded for other species are even lower. In fact, densities may be higher in these small montane forest

Table 2. Seasonal estimates of abundance derived using three estimators - the null estimator $\left(N_{\mathrm{o}}\right)$, Darroch's estimator $\left(N_{\mathrm{d}}\right)$ and the generalized removal estimator $\left(N_{\mathrm{r}}\right)$ and their coefficients of variation from 2, 3, 4 and 5 days of trapping. ${ }^{a}$

\begin{tabular}{|c|c|c|c|c|c|c|c|c|}
\hline Sampling session & $N_{\mathrm{o}}$ & $\begin{array}{l}\mathrm{CV} \\
(\%)\end{array}$ & $N_{\mathrm{r}}$ & $\begin{array}{l}\mathrm{CV} \\
(\%)\end{array}$ & $N_{\mathrm{d}}$ & $\begin{array}{l}\mathrm{CV} \\
(\%)\end{array}$ & MNA & $\begin{array}{c}\text { Capture } \\
\text { probability }\end{array}$ \\
\hline \multicolumn{9}{|l|}{2 day estimates } \\
\hline 1 & $6 \cdot 4$ & $38 \cdot 4$ & $8 \cdot 4$ & $29 \cdot 8$ & & & $5 \cdot 3$ & $0 \cdot 5$ \\
\hline 2 & $10 \cdot 3$ & $26 \cdot 3$ & $10 \cdot 0$ & $20 \cdot 8$ & & & $6 \cdot 9$ & $0 \cdot 6$ \\
\hline 3 & $8 \cdot 5$ & $15 \cdot 0$ & $11 \cdot 6$ & $18 \cdot 1$ & & & $8 \cdot 0$ & 0.7 \\
\hline 4 & $11 \cdot 7$ & $20 \cdot 8$ & $12 \cdot 4$ & $17 \cdot 5$ & & & $9 \cdot 3$ & $0 \cdot 6$ \\
\hline \multicolumn{9}{|l|}{3 day estimates } \\
\hline 1 & $10 \cdot 0$ & $30 \cdot 4$ & $11 \cdot 7$ & $24 \cdot 7$ & $10 \cdot 0$ & $26 \cdot 2$ & $7 \cdot 7$ & $0 \cdot 37$ \\
\hline 2 & $12 \cdot 3$ & $31 \cdot 7$ & $14 \cdot 5$ & $28 \cdot 2$ & 11.9 & $15 \cdot 3$ & $9 \cdot 8$ & $0 \cdot 38$ \\
\hline 3 & $10 \cdot 7$ & $14 \cdot 4$ & $13 \cdot 7$ & $18 \cdot 8$ & $10 \cdot 4$ & $7 \cdot 6$ & $10 \cdot 0$ & 0.53 \\
\hline 4 & $12 \cdot 7$ & $9 \cdot 1$ & $18 \cdot 7$ & $23 \cdot 9$ & $16 \cdot 3$ & $5 \cdot 1$ & $12 \cdot 4$ & $0 \cdot 60$ \\
\hline \multicolumn{9}{|l|}{4 day estimates } \\
\hline 1 & $11 \cdot 3$ & $25 \cdot 6$ & $15 \cdot 1$ & $26 \cdot 6$ & $10 \cdot 6$ & $19 \cdot 5$ & $9 \cdot 6$ & $0 \cdot 34$ \\
\hline 2 & $13 \cdot 4$ & $20 \cdot 4$ & $18 \cdot 8$ & $25 \cdot 8$ & $13 \cdot 0$ & $13 \cdot 9$ & $12 \cdot 0$ & $0 \cdot 38$ \\
\hline 3 & $10 \cdot 7$ & $8 \cdot 4$ & $14 \cdot 6$ & $18 \cdot 9$ & $10 \cdot 7$ & $1 \cdot 2$ & $11 \cdot 1$ & 0.53 \\
\hline 4 & $14 \cdot 1$ & $6 \cdot 3$ & $21 \cdot 0$ & $24 \cdot 6$ & $10 \cdot 0$ & $0 \cdot 7$ & $14 \cdot 6$ & 0.56 \\
\hline \multicolumn{9}{|l|}{5 day estimates } \\
\hline 1 & $12 \cdot 0$ & $14 \cdot 4$ & $16 \cdot 7$ & $32 \cdot 1$ & $9 \cdot 6$ & $8 \cdot 4$ & $11 \cdot 0$ & $0 \cdot 33$ \\
\hline 2 & $13 \cdot 8$ & $13 \cdot 5$ & $19 \cdot 0$ & $16 \cdot 5$ & $12 \cdot 4$ & $11 \cdot 4$ & $13 \cdot 3$ & $0 \cdot 35$ \\
\hline 3 & $11 \cdot 6$ & $7 \cdot 4$ & $16 \cdot 5$ & $18 \cdot 3$ & $10 \cdot 3$ & $1 \cdot 5$ & $12 \cdot 1$ & 0.53 \\
\hline 4 & $14 \cdot 1$ & $9 \cdot 8$ & $18 \cdot 9$ & $12 \cdot 6$ & $13 \cdot 0$ & $0 \cdot 1$ & $15 \cdot 4$ & 0.53 \\
\hline
\end{tabular}

${ }^{a}$ The estimates and $\mathrm{CVs}$ are averaged for all plots for each of the four sampling sessions. MNA is the minimum number alive and capture probability is estimated using the null model. 
patches than in other contiguous habitats (Shanker and Sukumar 1998). Further, densities were highly variable and not synchronous between patches (Shanker and Sukumar 1999), making it difficult to use comparable estimators in a given sampling session. The null model, $M_{\mathrm{o}}$, may be selected when none of the other estimators give a good fit, and sample sizes where models may be fitted are only attained after 5 days of trapping or more (White et al 1982; Menkens and Anderson 1988). Therefore, the fact that the null model was chosen most frequently may reflect the inadequacy of the sample size rather than equal capture probabilities.

The coefficient of variation of the density estimate depends on capture probability and the number of days of capture. However, animals tend to lose body mass between successive captures due to the stress of capture, food deprivation or dehydration (Slade and Iskjaer 1990). In this study, trap mortality increased with the number of times an animal was recaptured, and hence the total proportion of animals dead increased with the number of days of sampling. This clearly means that for a CMR study where one would want to resample plots and study temporal variation or persistence, one cannot sample for an indefinite number of days. Further, high trap mortality results in unreliable estimates of density (Otis et al 1978). In fact, the number of animals known alive on the plot is the same on day 5 as on day 4 in this analysis. This would imply that, given this trap mortality, one should sample for 4 days at the most. Trapping effort was subsequently modified in this study to minimize mortality (Shanker 1998). Although Darroch's estimator had the lowest $\mathrm{CV}$, there is a suggestion that both this and the null estimator might be negatively biased. While the removal estimator gave higher estimates, its high CV makes it unreliable. From the data on mortality and the CVs of the estimators, one could conclude that 4 days of trapping is ideal for this location. However, analysis of the medium and small patches separately showed that estimates from 3 days were as good (or as bad) as estimates from 4 and 5 days.

It is clear, however, that there is no standard number of days of trapping that can be used as a rule of thumb for tropical forests. Even within a habitat, there may be differences between patches (based on patch size in this study). If one assumes that density estimation and repeated measurements of the site are required (in which case the population should not be depleted by trap mortality or removal trapping), the exact number of days of trapping depends on a variety of factors, including (i) capture probability and consequent $\mathrm{CV}$ of the estimate, and (ii) trap mortality. In this study, as in most studies in India (Prakash et al 1996; Ajith Kumar, unpublished results, Ravi Chellam, unpublished results), Sherman standard traps were used, which allow only a minimal quantity of food and bedd- ing material. Given the altitude $(>2000 \mathrm{msl})$ and climate (> $1500 \mathrm{~mm}$ rainfall) in this study, the only effective method to reduce mortality was found to be reducing the number of days of trapping in each trapping session. While this may compromise density estimation in a given trapping session, the reduction of mortality is necessary to enable resampling. Further, ethical and biological considerations require that one must attempt to reduce mortality as far as possible.

When population sizes and capture probabilities are very low, CMR models cannot be applied (White et al 1982). Since population sizes were frequently very low in all plots and appropriate models could not be applied to all sampling sessions, MNA was used to derive density estimates. In tropical forests with low densities and low capture probabilities, one may not able to obtain abundance or density estimates that are satisfactory. Under these circumstances, it may be better to focus on questions where density is not a central issue. While it may be fruitful to deal with questions where the estimation of density is not required and interesting information may be acquired, there are situations where the biologist needs to deal with population size. It is necessary therefore to deal with this problem of estimating the size of these small populations. Furthermore, the attempts made here at density estimation are confined to a single species and other species are even fewer in number with practically no recaptures. Capture probabilities are higher in some seasons than others and estimates of density may be best obtained at these times. Finally, it is recommended that since the variation in species composition and density is high between tropical forests, it is absolutely imperative that each study examine the small mammal population of the forest in an initial phase and base the rest of the study on these findings, and especially not depend on general recommendations based on studies from temperate forests.

\section{Acknowledgements}

This work was supported by a grant from the Ministry of Environment and Forests, New Delhi and The John D and Catherine T MacArthur Foundation, USA. The support of the Tamil Nadu Forest Department and the Tamil Nadu Electricity Board was essential for the field work. I am grateful to $\mathrm{R}$ Sukumar for supporting me through the duration of the project. Many thanks to $\mathrm{N}$ V Joshi and Rana for helping with analysis, commenting on drafts and being good listeners. I would also like to thank two anonymous referees for their comments on the manuscript.

\section{Appendix 1}

Four small patches, each with a single 0.49 ha plot, were sampled two to four times $(n=10)$; the medium sized patch (60 ha) 
had two 0.49 ha plots $(n=7)$ and the large patch $(600 \mathrm{ha})$ had three 0.49 ha plots sampled two to four times and two 1 ha plots which were sampled once $(n=12)$.

Appendix 1a: Estimates of abundance derived using two estimators - the null estimator $\left(N_{\mathrm{o}}\right)$, and the generalized removal estimator $\left(N_{\mathrm{r}}\right)$ and their coefficients of variation from two days of trapping.

\begin{tabular}{|c|c|c|c|c|c|c|c|c|}
\hline Shola & Session & Model & $N_{\mathrm{o}}$ & $\mathrm{CV}$ & $N_{\mathrm{r}}$ & $\mathrm{CV}$ & MNA & $\begin{array}{c}\text { Capture } \\
\text { probability }\end{array}$ \\
\hline Small 1 & 1 & $M_{\mathrm{bh}}$ & $7 \cdot 00$ & $44 \cdot 29$ & $7 \cdot 00$ & $28 \cdot 57$ & 5.00 & 0.46 \\
\hline Small 1 & 2 & $M_{\mathrm{bh}}$ & & & $2 \cdot 00$ & 0.00 & $2 \cdot 00$ & \\
\hline Small 2 & 1 & $M_{\mathrm{tbh}}$ & $7 \cdot 00$ & $22 \cdot 86$ & $10 \cdot 00$ & $28 \cdot 00$ & $6 \cdot 00$ & $0 \cdot 61$ \\
\hline Small 2 & 2 & $M_{\mathrm{tbh}}$ & $11 \cdot 00$ & $21 \cdot 82$ & $13 \cdot 00$ & $21 \cdot 54$ & $9 \cdot 00$ & 0.57 \\
\hline Small 3 & 1 & $M_{\mathrm{tbh}}$ & $7 \cdot 00$ & $44 \cdot 29$ & $6 \cdot 00$ & $23 \cdot 33$ & $5 \cdot 00$ & 0.46 \\
\hline Small 3 & 2 & $M_{\mathrm{bh}} /_{\mathrm{tbh}}$ & 8.00 & $11 \cdot 25$ & $10 \cdot 00$ & $20 \cdot 00$ & 8.00 & $0 \cdot 75$ \\
\hline Small 3 & 3 & $M_{\mathrm{tbh}}$ & $6 \cdot 00$ & $3 \cdot 67$ & $7 \cdot 00$ & $20 \cdot 00$ & $6 \cdot 00$ & $0 \cdot 91$ \\
\hline Small 4 & 1 & $M_{\mathrm{tbh}}$ & & & $17 \cdot 00$ & $18 \cdot 82$ & $10 \cdot 00$ & \\
\hline Small 4 & 2 & $M_{\mathrm{tbh}}$ & $13 \cdot 00$ & $15 \cdot 38$ & $16 \cdot 00$ & $17 \cdot 50$ & $12 \cdot 00$ & $0 \cdot 64$ \\
\hline Small 4 & 3 & $M_{\mathrm{tbh}}$ & & & $17 \cdot 00$ & $21 \cdot 76$ & $10 \cdot 00$ & \\
\hline Medium 1 & 2 & $M_{\mathrm{tbh}}$ & & & $8 \cdot 00$ & $31 \cdot 25$ & $5 \cdot 00$ & \\
\hline Medium 1 & 3 & $M_{\mathrm{tbh}}$ & $9 \cdot 00$ & $18 \cdot 89$ & 11.00 & 22.73 & $8 \cdot 00$ & $0 \cdot 63$ \\
\hline Medium 1 & 4 & $M_{\mathrm{tbh}}$ & & & $5 \cdot 00$ & $0 \cdot 00$ & $5 \cdot 00$ & \\
\hline Medium 2 & 1 & $M_{\mathrm{tbh}}$ & $4 \cdot 00$ & $37 \cdot 50$ & $7 \cdot 00$ & $28 \cdot 57$ & $4 \cdot 00$ & 0.58 \\
\hline Medium 2 & 2 & $M_{\mathrm{bh}}$ & & & $6 \cdot 00$ & $33 \cdot 33$ & $4 \cdot 00$ & \\
\hline Medium 2 & 3 & $M_{\mathrm{tbh}}$ & $11 \cdot 00$ & $21 \cdot 82$ & $14 \cdot 00$ & $22 \cdot 86$ & 9.00 & 0.57 \\
\hline Medium 2 & 4 & $M_{\mathrm{tbh}}$ & $9 \cdot 00$ & $20 \cdot 00$ & $10 \cdot 00$ & $20 \cdot 00$ & $8 \cdot 00$ & $0 \cdot 63$ \\
\hline Large 1 & 1 & $M_{\mathrm{tbh}}$ & & & $4 \cdot 00$ & $50 \cdot 00$ & $2 \cdot 00$ & \\
\hline Large 1 & 2 & $M_{\mathrm{tbh}}$ & & & $13 \cdot 00$ & $19 \cdot 23$ & $9 \cdot 00$ & \\
\hline Large 1 & 3 & $M_{\mathrm{o}}$ & $9 \cdot 00$ & $20 \cdot 00$ & $12 \cdot 00$ & $20 \cdot 83$ & $8 \cdot 00$ & $0 \cdot 63$ \\
\hline Large 1 & 4 & $M_{\mathrm{tbh}}$ & 11.00 & $21 \cdot 82$ & $14 \cdot 00$ & $22 \cdot 86$ & $9 \cdot 00$ & 0.57 \\
\hline Large 2 & 1 & $M_{\mathrm{tbh}}$ & $7 \cdot 00$ & $42 \cdot 86$ & 8.00 & $31 \cdot 25$ & $5 \cdot 00$ & 0.46 \\
\hline Large 2 & 2 & $M_{\mathrm{tbh}}$ & $9 \cdot 00$ & $56 \cdot 67$ & $12 \cdot 00$ & $23 \cdot 33$ & $6 \cdot 00$ & $0 \cdot 38$ \\
\hline Large 2 & 3 & $M_{\mathrm{o}}$ & $3 \cdot 00$ & $10 \cdot 00$ & $3 \cdot 00$ & $0 \cdot 00$ & $3 \cdot 00$ & $0 \cdot 83$ \\
\hline Large 2 & 4 & $M_{\mathrm{tbh}}$ & $19 \cdot 00$ & $24 \cdot 21$ & $20 \cdot 00$ & $17 \cdot 50$ & $14 \cdot 00$ & $0 \cdot 49$ \\
\hline Large 3 & 3 & $M_{\mathrm{tbh}}$ & $13 \cdot 00$ & $15 \cdot 38$ & $17 \cdot 00$ & $18 \cdot 24$ & $12 \cdot 00$ & $0 \cdot 64$ \\
\hline Large 3 & 4 & $M_{\mathrm{bh}}$ & $7 \cdot 00$ & $15 \cdot 71$ & $9 \cdot 00$ & $22 \cdot 22$ & $7 \cdot 00$ & $0 \cdot 70$ \\
\hline Large 4 & 4 & $M_{\mathrm{bh}}$ & $16 \cdot 00$ & $11 \cdot 88$ & $19 \cdot 00$ & $14 \cdot 74$ & $15 \cdot 00$ & $0 \cdot 67$ \\
\hline Large 5 & 4 & $M_{\mathrm{tbh}}$ & $8 \cdot 00$ & $31 \cdot 25$ & $10 \cdot 00$ & $25 \cdot 00$ & $7 \cdot 00$ & 0.54 \\
\hline
\end{tabular}

Appendix 1b: Estimates of abundance derived using three estimators - the null estimator $\left(N_{\mathrm{o}}\right)$, Darroch's estimator $\left(N_{\mathrm{d}}\right)$, and the generalized removal estimator $\left(N_{\mathrm{r}}\right)$ and their coefficients of variation from two days of trapping.

\begin{tabular}{lclrrrrrrrr}
\hline Shola & Session & Model & $N_{\mathrm{o}}$ & $\mathrm{CV}$ & $N_{\mathrm{r}}$ & $\mathrm{CV}$ & $N_{\mathrm{d}}$ & $\mathrm{CV}$ & MNA & Probability \\
\hline Small 1 & 1 & $M_{\mathrm{o}}$ & 5 & $20 \cdot 00$ & 8 & $31 \cdot 25$ & 5 & $36 \cdot 00$ & 6 & $0 \cdot 53$ \\
Small 1 & 2 & $M_{\mathrm{o}}$ & 6 & $50 \cdot 00$ & 8 & $43 \cdot 75$ & 4 & $2 \cdot 25$ & 4 & $0 \cdot 30$ \\
Small 2 & 1 & $M_{\mathrm{o}}$ & 11 & $30 \cdot 00$ & 12 & $29 \cdot 17$ & 9 & $18 \cdot 89$ & 8 & $0 \cdot 35$ \\
Small 2 & 2 & $M_{\mathrm{o}}$ & 13 & $10 \cdot 77$ & 21 & $23 \cdot 33$ & 12 & $2 \cdot 50$ & 13 & $0 \cdot 55$ \\
Small 3 & 1 & $M_{\text {tbh }}$ bh & 5 & $0 \cdot 00$ & 5 & $0 \cdot 00$ & & & 5 & $0 \cdot 53$ \\
Small 3 & 2 & $M_{\mathrm{o}}$ & 10 & $14 \cdot 00$ & 17 & $24 \cdot 71$ & 10 & $7 \cdot 50$ & 11 & $0 \cdot 52$ \\
Small 3 & 3 & $M_{\mathrm{o}}$ & 9 & $8 \cdot 89$ & 15 & $28 \cdot 00$ & 9 & $0 \cdot 11$ & 9 & $0 \cdot 63$ \\
Small 4 & 1 & $M_{\mathrm{o}}$ th & 13 & $32 \cdot 31$ & 15 & $16 \cdot 67$ & 13 & $26 \cdot 15$ & 13 & $0 \cdot 31$ \\
Small 4 & 2 & $M_{\mathrm{o}}$ & 12 & $7 \cdot 50$ & 13 & $19 \cdot 23$ & 12 & $1 \cdot 42$ & 13 & $0 \cdot 64$ \\
Small 4 & 3 & $M_{\mathrm{o}}$ & 11 & $16 \cdot 36$ & 10 & $0 \cdot 00$ & 11 & $9 \cdot 00$ & 10 & $0 \cdot 48$ \\
Medium 1 & 2 & $M_{\mathrm{o}}$ & 11 & $40 \cdot 00$ & 11 & $31 \cdot 82$ & 10 & $33 \cdot 00$ & 7 & $0 \cdot 23$ \\
Medium 1 & 3 & $M_{\mathrm{o}}$ & 12 & $20 \cdot 83$ & 14 & $25 \cdot 00$ & 12 & $15 \cdot 83$ & 10 & $0 \cdot 42$ \\
Medium 1 & 4 & $M_{\text {th }}$ & 7 & $7 \cdot 14$ & 11 & $31 \cdot 82$ & & & 7 & $0 \cdot 71$ \\
Medium 2 & 1 & $M_{\mathrm{o}}$ & 20 & $49 \cdot 00$ & 23 & $26 \cdot 09$ & 17 & $37 \cdot 65$ & 11 & $0 \cdot 20$ \\
Medium 2 & 2 & $M_{\text {th }}$ & 9 & $58 \cdot 89$ & 7 & $35 \cdot 71$ & & & 5 & $0 \cdot 23$ \\
Medium 2 & 3 & $M_{\mathrm{o}}$ & 9 & $7 \cdot 78$ & 9 & $0 \cdot 00$ & 9 & $0 \cdot 11$ & 9 & $0 \cdot 67$ \\
Medium 2 & 4 & $M_{\mathrm{o}}$ & 9 & $8 \cdot 89$ & 11 & $22 \cdot 73$ & 9 & $0 \cdot 11$ & 9 & $0 \cdot 63$ \\
Large 1 & 1 & $M_{\mathrm{h}}$ & 9 & $58 \cdot 89$ & 11 & $38 \cdot 18$ & & & 5 & $0 \cdot 23$ \\
Large 1 & 2 & $M_{\mathrm{o}}$ & 24 & $40 \cdot 00$ & 22 & $22 \cdot 27$ & 23 & $34 \cdot 78$ & 14 & $0 \cdot 22$ \\
Large 1 & 3 & $M_{\mathrm{o}}$ & 11 & $16 \cdot 36$ & 15 & $23 \cdot 33$ & 11 & $11 \cdot 82$ & 11 & $0 \cdot 48$ \\
Large 1 & 4 & $M_{\text {tbh }}$ & 12 & $9 \cdot 17$ & 18 & $23 \cdot 33$ & & & 12 & $0 \cdot 59$ \\
Large 2 & 1 & $M_{\mathrm{o}}$ & 7 & $22 \cdot 86$ & 8 & $31 \cdot 25$ & 6 & $12 \cdot 50$ & 6
\end{tabular}


Appendix 16 contd.

\begin{tabular}{lllrrrrrrrr}
\hline Large 2 & 2 & $M_{\mathrm{o}}$ & 13 & $32 \cdot 31$ & 17 & $24 \cdot 71$ & 12 & $25 \cdot 83$ & 11 & $0 \cdot 31$ \\
Large 2 & 3 & $M_{\mathrm{o}}$ & 7 & $22 \cdot 86$ & 12 & $35 \cdot 00$ & 6 & $12 \cdot 50$ & 6 & $0 \cdot 45$ \\
Large 2 & 4 & $M_{\mathrm{o}}$ & 19 & $12 \cdot 11$ & 26 & $18 \cdot 85$ & 19 & $8 \cdot 95$ & 18 & $0 \cdot 49$ \\
Large 3 & 3 & $M_{\mathrm{o}}$ & 16 & $7 \cdot 50$ & 21 & $20 \cdot 00$ & 15 & $3 \cdot 80$ & 15 & $0 \cdot 60$ \\
Large 3 & 4 & $M_{\text {tbh }} / M_{\mathrm{o}}$ & 10 & $8 \cdot 00$ & 16 & $26 \cdot 25$ & & & 10 & $0 \cdot 63$ \\
Large 4 & 4 & $M_{\mathrm{o}}$ & 21 & $8 \cdot 10$ & 30 & $18 \cdot 33$ & 21 & $6 \cdot 19$ & 20 & $0 \cdot 56$ \\
Large 5 & 4 & $M_{\text {th }}$ & 11 & $10 \cdot 00$ & 19 & $25 \cdot 79$ & & & 11 & $0 \cdot 59$ \\
\hline
\end{tabular}

Appendix 1c: Estimates of abundance and their coefficients of variation derived from four days of trapping.

\begin{tabular}{|c|c|c|c|c|c|c|c|c|c|c|}
\hline Shola & Session & Model & $N_{\mathrm{o}}$ & $\mathrm{CV}$ & $N_{\mathrm{r}}$ & $\mathrm{CV}$ & $N_{\mathrm{d}}$ & $\mathrm{CV}$ & MNA & Probability \\
\hline Small 1 & 1 & $M_{\mathrm{o}}$ & 12 & $44 \cdot 17$ & 18 & $33 \cdot 33$ & 11 & $34 \cdot 55$ & 9 & $0 \cdot 20$ \\
\hline Small 1 & 2 & $M_{\mathrm{o}}$ & 7 & $30 \cdot 00$ & 12 & $40 \cdot 83$ & 6 & $12 \cdot 33$ & 6 & $0 \cdot 31$ \\
\hline Small 2 & 1 & $M_{\mathrm{o}}$ & 9 & $12 \cdot 22$ & 12 & $29 \cdot 17$ & 9 & $0 \cdot 22$ & 9 & 0.46 \\
\hline Small 2 & 2 & $M_{\mathrm{o}}$ & 11 & $3 \cdot 64$ & 13 & $0 \cdot 00$ & 11 & $0 \cdot 09$ & 13 & $0 \cdot 64$ \\
\hline Small 3 & 1 & $M_{\mathrm{o}}$ & 6 & $15 \cdot 00$ & 9 & $38 \cdot 89$ & & & 6 & 0.46 \\
\hline Small 3 & 2 & $M_{\mathrm{o}}$ & 11 & $13 \cdot 64$ & 23 & $26 \cdot 09$ & 11 & $8 \cdot 55$ & 14 & 0.42 \\
\hline Small 3 & 3 & $M_{\mathrm{o}}$ & 8 & $5 \cdot 00$ & 9 & $0 \cdot 00$ & 8 & $0 \cdot 13$ & 9 & 0.63 \\
\hline Small 4 & 1 & $M_{\mathrm{o}}$ & 14 & $30 \cdot 71$ & 21 & $23 \cdot 33$ & 14 & $26 \cdot 43$ & 15 & $0 \cdot 24$ \\
\hline Small 4 & 2 & $M_{\mathrm{o}}$ & 13 & $3 \cdot 85$ & 17 & $20 \cdot 59$ & 13 & 0.08 & 14 & $0 \cdot 64$ \\
\hline Small 4 & 3 & $M_{\mathrm{o}}$ & 9 & $10 \cdot 00$ & 14 & $25 \cdot 00$ & 9 & $0 \cdot 11$ & 11 & $0 \cdot 50$ \\
\hline Medium 1 & 2 & $M_{\mathrm{o}}$ & 17 & $38 \cdot 24$ & 19 & 31.58 & 17 & $32 \cdot 94$ & 10 & $0 \cdot 20$ \\
\hline Medium 1 & 3 & $M_{\mathrm{o}}$ & 10 & $9 \cdot 90$ & 10 & $0 \cdot 00$ & 10 & $3 \cdot 00$ & 10 & 0.49 \\
\hline Medium 1 & 4 & $M_{\mathrm{o}}$ & 7 & $4 \cdot 29$ & 11 & $31 \cdot 82$ & 7 & $0 \cdot 14$ & 8 & 0.68 \\
\hline Medium 2 & 1 & $M_{\mathrm{tbh}} / M_{\mathrm{o}}$ & 17 & $19 \cdot 41$ & 23 & $26 \cdot 09$ & & & 14 & $0 \cdot 30$ \\
\hline Medium 2 & 2 & $M_{\mathrm{o}}$ & 7 & $30 \cdot 00$ & 9 & $38 \cdot 89$ & 7 & $20 \cdot 00$ & 6 & $0 \cdot 31$ \\
\hline Medium 2 & 3 & $M_{\mathrm{o}}$ & 10 & $6 \cdot 00$ & 13 & $26 \cdot 92$ & 10 & $0 \cdot 20$ & 10 & $0 \cdot 60$ \\
\hline Medium 2 & 4 & $M_{\mathrm{o}}$ & 11 & $8 \cdot 18$ & 17 & $28 \cdot 82$ & 11 & 1.82 & 11 & 0.52 \\
\hline Large 1 & 1 & $M_{\mathrm{o}}$ & 15 & $48 \cdot 00$ & 17 & $35 \cdot 29$ & 13 & $36 \cdot 15$ & 8 & $0 \cdot 16$ \\
\hline Large 1 & 2 & $M_{\mathrm{o}}$ & 21 & $16 \cdot 19$ & 30 & $23 \cdot 00$ & 20 & $13 \cdot 00$ & 18 & $0 \cdot 31$ \\
\hline Large 1 & 3 & $M_{\mathrm{o}}$ & 11 & $8 \cdot 18$ & 15 & $23 \cdot 33$ & 11 & 0.73 & 12 & $0 \cdot 52$ \\
\hline Large 1 & 4 & $M_{\mathrm{o}} / M_{\mathrm{tbh}}$ & 12 & $5 \cdot 83$ & 16 & $21 \cdot 88$ & 12 & 0.08 & 13 & 0.58 \\
\hline Large 2 & 1 & $M_{\mathrm{o}}$ & 6 & $10 \cdot 00$ & 6 & 0.00 & 6 & $0 \cdot 17$ & 6 & $0 \cdot 54$ \\
\hline Large 2 & 2 & $M_{\mathrm{o}}$ & 20 & $27 \cdot 50$ & 27 & $25 \cdot 56$ & 19 & $24 \cdot 21$ & 15 & $0 \cdot 23$ \\
\hline Large 2 & 3 & $M_{\mathrm{o}}$ & 8 & $13 \cdot 75$ & 14 & $35 \cdot 00$ & 8 & $0 \cdot 13$ & 8 & $0 \cdot 46$ \\
\hline Large 2 & 4 & $M_{\mathrm{h}}$ & 22 & $9 \cdot 55$ & 30 & $20 \cdot 00$ & & & 21 & 0.42 \\
\hline Large 3 & 3 & $M_{\mathrm{o}}$ & 19 & $6 \cdot 32$ & 27 & $22 \cdot 22$ & 19 & $3 \cdot 84$ & 18 & 0.51 \\
\hline Large 3 & 4 & $M_{\mathrm{tbh}}$ & 12 & $8 \cdot 08$ & 26 & $26 \cdot 54$ & & & 14 & $0 \cdot 51$ \\
\hline Large 4 & 4 & $M_{\mathrm{h}}$ & 22 & $3 \cdot 64$ & 28 & $17 \cdot 50$ & & & 22 & $0 \cdot 60$ \\
\hline Large 5 & 4 & $M_{\mathrm{tb}} / M_{\mathrm{th}}$ & 13 & $4 \cdot 62$ & 19 & $25 \cdot 79$ & & & 13 & $0 \cdot 61$ \\
\hline
\end{tabular}

Appendix 1d: Estimates of abundance and their coefficients of variation derived from five days of trapping.

\begin{tabular}{|c|c|c|c|c|c|c|c|c|c|c|}
\hline Shola & Session & Model & $N_{\mathrm{o}}$ & $\mathrm{CV}$ & $N_{\mathrm{r}}$ & $\mathrm{CV}$ & $N_{\mathrm{d}}$ & $\mathrm{CV}$ & MNA & Probability \\
\hline Small 1 & 1 & $M_{\mathrm{o}}$ & 9 & $14 \cdot 44$ & 14 & $32 \cdot 14$ & 8 & $0 \cdot 13$ & 10 & $0 \cdot 35$ \\
\hline Small 1 & 2 & $M_{\mathrm{o}}$ & 7 & $21 \cdot 43$ & 6 & 0.00 & 6 & $5 \cdot 00$ & 6 & $0 \cdot 30$ \\
\hline Small 2 & 1 & $M_{\mathrm{o}}$ & 10 & $10 \cdot 00$ & 14 & $32 \cdot 14$ & 10 & $5 \cdot 00$ & 10 & $0 \cdot 41$ \\
\hline Small 2 & 2 & $M_{\mathrm{o}}$ & 11 & 2.73 & & & 11 & 0.09 & 13 & 0.64 \\
\hline Small 3 & 1 & $M_{\mathrm{o}}$ & 10 & $21 \cdot 00$ & 16 & $39 \cdot 38$ & 9 & $16 \cdot 67$ & 8 & $0 \cdot 28$ \\
\hline Small 3 & 2 & $M_{\mathrm{o}}$ & 17 & $21 \cdot 76$ & 34 & $26 \cdot 18$ & 17 & $18 \cdot 24$ & 18 & $0 \cdot 23$ \\
\hline Small 3 & 3 & $M_{\mathrm{o}}$ & 8 & $3 \cdot 75$ & & & 8 & $0 \cdot 13$ & 9 & $0 \cdot 60$ \\
\hline Small 4 & 1 & $M_{\mathrm{o}}$ & 14 & $6 \cdot 67$ & 20 & $22 \cdot 50$ & 14 & $20 \cdot 00$ & 16 & $0 \cdot 24$ \\
\hline Small 4 & 2 & $M_{\mathrm{o}}$ & 12 & $2 \cdot 50$ & 14 & 0.00 & 12 & 0.08 & 14 & 0.58 \\
\hline Small 4 & 3 & $M_{\mathrm{o}}$ & 9 & $2 \cdot 31$ & 11 & 0.00 & 9 & $0 \cdot 11$ & 11 & 0.49 \\
\hline Medium 1 & 2 & $M_{\mathrm{o}}$ & 13 & $26 \cdot 92$ & 10 & $0 \cdot 00$ & 13 & $22 \cdot 31$ & 10 & $0 \cdot 20$ \\
\hline Medium 1 & 3 & $M_{\mathrm{o}}$ & 13 & $12 \cdot 31$ & 20 & $31 \cdot 50$ & 13 & $8 \cdot 46$ & 12 & 0.55 \\
\hline Medium 1 & 4 & $M_{\mathrm{o}}$ & 6 & $5 \cdot 00$ & 8 & 0.00 & 6 & $0 \cdot 17$ & 8 & 0.55 \\
\hline Medium 2 & 1 & $M_{\mathrm{tbh}} / M_{\mathrm{o}}$ & 16 & $12 \cdot 50$ & 19 & 23.68 & & & 15 & $0 \cdot 33$ \\
\hline Medium 2 & 2 & $M_{\mathrm{o}}$ & 9 & $23 \cdot 33$ & 11 & $40 \cdot 91$ & 8 & $20 \cdot 00$ & 7 & $0 \cdot 26$ \\
\hline Medium 2 & 3 & $M_{\mathrm{o}}$ & 11 & $4 \cdot 55$ & 15 & $30 \cdot 00$ & 11 & 0.09 & 11 & $0 \cdot 55$ \\
\hline
\end{tabular}


Appendix 1d contd.

\begin{tabular}{|c|c|c|c|c|c|c|c|c|c|c|}
\hline Medium 2 & 4 & $M_{\mathrm{o}}$ & 11 & $6 \cdot 36$ & 11 & $0 \cdot 00$ & 11 & $0 \cdot 09$ & 11 & $0 \cdot 49$ \\
\hline Large 1 & 1 & $M_{\mathrm{o}} / M_{\mathrm{h}}$ & 18 & $23 \cdot 57$ & 23 & $33 \cdot 91$ & & & 11 & $0 \cdot 17$ \\
\hline Large 1 & 2 & $M_{\mathrm{o}} / M_{\mathrm{h}}$ & 21 & $3 \cdot 33$ & 28 & $22 \cdot 50$ & & & 20 & $0 \cdot 31$ \\
\hline Large 1 & 3 & $M_{\mathrm{o}}$ & 13 & $6 \cdot 67$ & 22 & $28 \cdot 64$ & 13 & $0 \cdot 08$ & 14 & 0.49 \\
\hline Large 1 & 4 & $M_{\mathrm{o}} / M_{\mathrm{th}}$ & 11 & $32 \cdot 78$ & 13 & $0 \cdot 00$ & 11 & $0 \cdot 09$ & 13 & $0 \cdot 53$ \\
\hline Large 2 & 1 & $M_{\mathrm{o}}$ & 7 & $12 \cdot 86$ & 11 & $40 \cdot 91$ & 7 & $0 \cdot 14$ & 7 & $0 \cdot 54$ \\
\hline Large 2 & 2 & $M_{\mathrm{o}}$ & 20 & 5.69 & 30 & $25 \cdot 67$ & 20 & $14 \cdot 00$ & 18 & $0 \cdot 25$ \\
\hline Large 2 & 3 & $M_{\mathrm{o}}$ & 8 & $5 \cdot 45$ & 8 & 0.00 & 8 & $0 \cdot 13$ & 8 & $0 \cdot 50$ \\
\hline Large 2 & 4 & $M_{\mathrm{h}}$ & 22 & $5 \cdot 71$ & 26 & $17 \cdot 31$ & & & 22 & $0 \cdot 43$ \\
\hline Large 3 & 3 & $M_{\mathrm{bh}}$ & 19 & $17 \cdot 00$ & 23 & $19 \cdot 57$ & & & 20 & $0 \cdot 50$ \\
\hline Large 3 & 4 & $M_{\mathrm{tbh}}$ & 12 & $7 \cdot 50$ & 19 & 23.68 & & & 15 & $0 \cdot 47$ \\
\hline Large 4 & 4 & $M_{\mathrm{o}}$ & 24 & $6 \cdot 36$ & 32 & $19 \cdot 69$ & 24 & $0 \cdot 04$ & 24 & $0 \cdot 60$ \\
\hline Large 5 & 4 & $M_{\mathrm{b}}$ & 13 & $4 \cdot 74$ & 23 & $27 \cdot 39$ & & & 15 & 0.63 \\
\hline
\end{tabular}

\section{References}

August P V 1983 The role of habitat complexity and heterogeneity in structuring tropical mammal communities; Ecology 64 1495-1507

Boonstra R and Boag P T 1992 Spring declines in Microtus pennsylvanicus and the role of steroid hormones; $J$. Anim. Ecol. 61 339-352

Brownie C and Pollock K H 1985 Analysis of multiple capture recapture data using band recovery methods; Biometrics 41 411-420

Burnham K P and Overton W S 1969 A simulation study of live trapping and estimation of population size; Technical Report Number 14, Department of Statistics, Oregon University, USA

Carothers A D 1973 Capture Recapture methods applied to a population with known parameters; J. Anim. Ecol. 42 $125-146$

Chandrasekhar-Rao A and Sunquist M E 1996 Ecology of small mammals in tropical forest habitats of southern India; J. Trop. Ecol. 12 561-571

Diffendorfer J E, Gaines M S and Holt R D 1995 Habitat fragmentation and movements of three small mammals (Sigmodon, Microtus, and Peromyscus); Ecology 76827 839

Doonan T J and Slade N A 1995 Effects of supplemental food on population dynamics of cotton rats, Sigmodon hispidus; Ecology 76 814-826

Harrison J L 1969 The abundance and population density of mammals in Malayan lowland forests; Malay. Nat. J. 22 174-178

Hilborn R, Redfield J A and Krebs C J 1976 On the reliability of enumeration for mark and recapture census of voles; Can. J. Zool. 54 1019-1024

Iriarte J A, Contreras L C and Jaksic F M 1989 A long-term study of a small-mammal assemblage in the Central Chilean matorral; J. Mammal. 70 79-87

Isabirye-Basuta G and Kasenene J M 1987 Small rodent populations in selectively felled and mature tracts of Kibale Forest, Uganda; Biotropica 12 260-266

Jackson C H N 1933 On the true density of tsetse flies; $J$. Anim. Ecol. 2 204-209

Jedrzejewski W, Jedrzejewski B and Szymura L 1995 Weasel population response, home range and predation on rodents in a deciduous forest in Poland; Ecology 76 179195

Jeffery S M 1977 Rodent ecology and land use in western Ghana; J. Appl. Ecol. 14 741-755

Jolly G M and Dickson J M 1983 The problem of unequal catchability in mark-recapture estimation of small mammal populations; Can. J. Zool. $61922-927$

Krebs C J 1966 Demographic changes in fluctuating populations of Microtus californicus; Ecol. Monogr. 36 239273

Lebreton J D, Burnham K M, Clobert J and Anderson J R 1992 Modelling Survival and Testing Biological Hypothesis Using Marked Animals A Unified Approach with Case Studies; Ecol. Monogr. 62 67-118

Lincoln F C 1930 Calculating waterfowl abundances on the basis of banding returns; Circ. U.S. Depart. Agricul. 118 $1-4$

Mares M A and Ernest K A 1995 Population and community ecology of small mammals in a gallery forest of central Brazil; J. Mammal. 76 750-768

McMurry S T, Lochmiller R L, Boggs J F, Leslie D M Jr and Engle D M 1994 Demographic profiles of cotton rats in a continuum of habitat types; J. Mammal. 75 50-59

Meena V 1997 Small mammal communities of Mudumalai Wildlife Sanctuary southern India; M S Thesis, Pondicherry University, Pondicherry

Meher-Homji V M 1984 Udhagamandalam (Ootacamund): A biogeographic perspective; Indian Geogr. J. 59 205-213

Menkens G E Jr and Anderson S H 1988 Estimation of Small Mammal Population Size; Ecology 69 1952-1959

Minta S and Mangel M 1989 A simple population estimate based on simulation for capture recapture and capture resight data; Ecology 70 1738-1751

Murua R, Meserve P L, Gonzalez L A and Jofre C 1987 The small mammal community of a Chilean temperate rain forest lack of evidence of competition between dominant species; J. Mammal. 68 729-738

Nichols J D, Noon B R, Stokes S L and Hines J E 1981 Remarks on the use of the capture recapture methodology in estimating avian population size; Studies Avian Biol. 6 $121-136$

Nichols J D and Pollock K H 1983 Estimating taxonomic diversity, extinction rates and speciation rates from fossil data using capture recapture methods; Paleobiology 9 $150-163$

Nichols J D 1992 Capture-Recapture Models; using marked animals to study population dynamics; BioScience $\mathbf{4 2}$ 94-102

O' Connell M A 1989 Population dynamics of neotropical small mammals in seasonal habitats; J. Mammal. 70 532548

O' Farrell M J, Kaufmann D W and Lundahl D W 1977 Use of live trapping with assessment line method for density estimation; J. Mammal. 58 575-585

Otis D L, Burnham K P, White G C and Anderson D R 1978 
Statistical Inference from Capture Data on Closed Animal Populations; Wildl. Monogr. 62

Patterson B D, Meserve P L and Lang B K 1989 Distribution and Abundance of small mammals along an elevational transect in temperate rainforests of Chile; J. Mammal. 70 $67-78$

Petersen C J G 1896 The yearly immigration of young plaice into the Limfjord from the German sea; Danish Biol. Stand. 6 1-48.

Pollock K H, Nichols J D, Brownie C and Hines J E 1990 Statistical Inference for Capture Recapture Experiments; Wildl. Monogr. 107

Prakash I, Partap Singh and Saravanan A 1996 Small Mammalian Diversity on Abu Hill; Proc. Indian Natl. Sci. Acad. B62 95-104

Schnabel Z E 1938 The estimation of the total fish population of a lake; Am. Math. Mon. 45 348-352

Scott D E and Dueser R D 1992 Habitat use by the insular populations of Mus and Peromyscus. What is the role of competition ?; J. Anim. Ecol. 61 329-338

Seber G A F 1982 Estimation of animal abundance and related parameters (London: Griffin)

Shanker K 1998 Community ecology of small mammals in montane ecosystems of the Upper Nilgiris, southern India;

$\mathrm{Ph} \mathrm{D}$ Thesis, Indian Institute of Science, Bangalore

Shanker K and Sukumar R 1998 Community ecology and demography of small mammal populations in insular montane forests in southern India; Oecologia 116243 251

Shanker K and Sukumar R 1999 Synchrony in small mammal populations of montane forest patches of southern India; J. Anim. Ecol. 68 50-59

Siegel S and Castellan N J Jr 1988 Nonparametric statistics for the behavioural sciences (New York: McGraw-Hill Book Company)

Skalski J R 1985 Construction of cost functions for tag recapture research; Wild. Soc. Bull. 13 273-283

Slade N A and Iskjaer C 1990 Daily variation in body mass of free-living rodents and its significance for mass-based population dynamics; J. Mammal. 71 357-363

Smith M H, Gardner R H, Gentry J B, Kaufmann D W and O' Farell M H 1975 Density estimations of small mammal populations; in Small mammals: their productivity and population dynamics (eds) F B Golley, K Petrusewicz and L Ryszkowski (New York: Cambridge University Press)

Steen H, Ims R A and Sonerud G A 1996 Spatial and temporal patterns of small-rodent population dynamics at a regional scale; Ecology 77 2365-2372

Stephenson P J 1993 The small mammal fauna of Reserve Speciale d'Annlamazaotra, Madagascar the effects of human disturbance on endemic species diversity; Biol. Cons. 2 603-615

Turner C L and Grant W E 1987 Effect of Sigmodon hispidus on microhabitat utilisation by Baiomys taylori and Reithrodontomys fulvescens; J. Mammal. 68 80-85

White G C, Anderson D R, Burnham K P and Otis D L 1982 Capture-recapture and removal methods for sampling closed populations (Los Alamos, New Mexico: Los Alamos National Laboratory)

Wileyto E P, Ewens W J and Mullen M A 1994 Markovrecapture population estimates: a tool for improving interpretation of trapping experiments; Ecology 75 1109-1117

Wirminghaus J O and Perrin M R 1993 Seasonal changes in density, demography and body composition of small mammals in a southern temperate forest; J. Zool. London 229 303-318

MS received 6 May 1999; accepted 7 December 1999

Corresponding editor: RENEE M BORGES 